\section{Resistance to "Castration-Resistant"}

In a recent article in The Oncologist, Merseburger et al. [1] outline perspectives arising from current progress in the treatment of advanced prostate cancer (PC). As a nonspecialist in this area, I found their account effectively addresses the challenges posed by this difficult clinical problem. However, I take this opportunity to challenge in turn the widely used phrase "castration resistance."

More than half a century ago, it was established that growth of PC was reduced by bilateral orchiectomy [2], and the rough term "castration" was commonly used. Then it was found that a similar therapeutic effect could be achieved alternatively by the administration of hormone-related agents such as diethylstilbestrol or goserelin [3]: such approaches became known as "chemical castration" (but the adjective was often dropped). Because the growth of PC (just as the development of the normal prostate itself) depends on androgens through androgen-receptor (AR) signaling, there was a sound rationale for these therapeutic procedures of androgen deprivation, frequently called more loosely "hormonal treatments."

Unfortunately, however, all of these beneficial interventions proved time-limited, as PC eventually resumes growth: one might have presumed that it had become independent of AR signaling. However, it transpired that things were not that simple. In an authoritative paper [4] published in 2004, the evidence was reviewed that when PC relapses after hormonal treatment, AR signaling is still on, due to two possible explanations: (a) androgens had not been completely eliminated (they are produced by the adrenal glands and sometimes by the PC itself); (b) even in complete absence of the androgen ligand, AR signaling can still operate through devious means (including AR mutation/amplification, crosstalk-mediated activation of other signaling pathways, and other mechanisms $[4,5])$. From then on, the phrase "castration-resistant PC" (CRPC) became popular ( $n=1,795$ in PubMed).

Perhaps the time has come to abrogate this term. First, from the clinical point of view for patients who have CRPC, there are now different remedies available depending on whether the resistance results from (a) or (b) above (e.g., abiraterone versus enzalutamide); thus, the term may cause confusion rather than clarity. Second, we should restore dignity to both patients and terminology. It was a disrespectful mistake in the past to indulge in the phrases "castration" and "chemical castration." CRPC is worse, and I have even come across the variant "castrationresistant patients," which some patients perceive as an accusation of refusing to accept something to which unfortunately they have been already subjected. One oncologist told me he used to use the term "castration resistance" freely, but, having PC himself, he has now changed his mind. Instead of CRPC, he suggests, for the two above-mentioned types, respectively, (a) "androgen-deprivation-resistant PC due to persistence of residual androgen" and (b) "androgen-depletionresistant PC due to androgen-independent persistence of AR signaling." I admit that these phrases are a bit cumbersome. More simply, androgen deprivation-resistant PC and androgen depletion-resistant PC could both be covered by ADRPC (and they could be called ADPRC-a, ADPRC-b), but the choice of appropriate acronyms is best left to the experts.

\section{LucIo LuzzATto}

Istituto Toscano Tumori, Florence, Italy

\section{Disclosures}

Lucio Luzzatto: GlaxoSmithKline (C/A) regarding antimalarial drugs. (C/A) Consulting/advisory relationship; (RF) Research funding; (E) Employment; (ET) Expert testimony; (H) Honoraria received; (OI) Ownership interests; (IP) Intellectual property rights/ inventor/patent holder; (SAB) Scientific advisory board

\section{REFERENCES}

1. Merseburger AS, Bellmunt J, Jenkins C et al. Perspectives on treatment of metastatic castration-resistant prostate cancer. The Oncologist 2013;18: 558-567.

2. Huggins C, Stevens RE, Hodges CV. Studies on prostate cancer:II. The effect of castration on advanced carcinoma of the prostate gland. Arch Surg 1941;43: 209-228.

3. Nelson W, Carter HB, DeWeese TI et al. A: Prostate cancer. In: Abeloff M, Armitage JO, Niederhuber JE et al., eds. Clinical Oncology, 3. Philadelphia, PA: Elsevier, 2004:2085-2148.

4. Scher HI, Buchanan G, Gerald W et al. Targeting the androgen receptor: Improving outcomes for castration-resistant prostate cancer. Endocr Relat Cancer 2004;11:459-476.

5. Hoimes $\mathrm{CJ}$, Kelly WK. Redefining hormone resistance in prostate cancer. Ther Adv Med Oncol 2010;2:107-123.

http://dx.doi.org/10.1634/theoncologist.2013-0363

\section{In Reply}

We thank Dr. Luzzatto for the comment discussing the term "castration resistant." Various phrases have been used to describe the progression of prostate cancer (PCa) following initial hormonal ablation therapy and include hormonerefractory $\mathrm{PCa}$, hormone-independent, or androgen-independent PCa. Recent developments in our understanding of the disease suggest that PCa progressing during treatment is not uniformly refractory to further hormonal and other manipulation/treatment, and the disease is heterogeneous between patients and within the same patient $[1,2]$.
The term "castration-resistant prostate cancer" (CRPC) is frequently used ( $n=1,795$ PubMed; date of our reply: $n=1,829$ ) and is also included in most guidelines defining this clinical scenario [3-5].

As discussed in our initial article, the recently approved novel agents such as abiraterone acetate, enzalutamide, cabazitaxel, and radium-223 have been shown to increase overall survival in advanced prostate cancer through various mechanisms [6]. The mechanisms of these novel agents are not limited to the androgen receptor (AR) or alterations of the AR (splice variants, mutations/amplification, crosstalkmediated activation through other pathways, etc.) [7]. 